\title{
PROCESSO DE ESCOLHA DE BANCOS DE IMAGENS: APLICAÇÃO NO MARKETING BUSINESS TO BUSINESS
}

CAMILA DE MORAES BARBOSA BORGES, M.Sc.

camila.mexgemp@gmail.com

DELANE BOTELHO, D.Sc.

delane.botelho@fgv.br

\section{RESUMO}

Com a popularização das câmeras digitais e da internet, a indústria da fotografia ampliou suas fronteiras, em termos de volume, variedade e qualidade. Este artigo analisa os atributos considerados críticos pelos compradores de produtos de banco de imagens e sua relevância no processo de escolha do produto em ambiente de internet. A pesquisa se dividiu em duas fases: qualitativa e quantitativa. Procedeu-se a análise conjunta a um conjunto de dados de 78 empresas compradoras de imagens. 0 atributo mais relevante na escolha do banco de imagens ideal foi a disponibilidade de imagens em alta resolução para o layout do cliente, o que pode implicar em novos argumentos de venda e comunicação. Sugestões para pesquisa futura são discutidas à luz do conhecimento em marketing organizacional.

Palavras chave: Banco de imagens. Comportamento de compra organizacional. B2B. Atributos. Análise conjunta.

\begin{abstract}
With the popularization of digital cameras and the Internet, the stock photography agency market expanded its borders, in terms of volume, variety and quality. This article discusses the attributes considered critical by the purchasers of products from stock photography agencies and their relevance in the process of choosing the product in the Internet environment. The research was divided into two phases: qualitative and quantitative. There has been a joint analysis of the data set of 78 companies customers of stock photography agencies. The most important attribute in selecting the ideal stock photography agency was the availability of high-resolution images in the layout for the customer, which can bring in new arguments of sales and communication. Suggestions for future research are discussed in the light of knowledge in marketing organization.
\end{abstract}

Key Works: Stock photography agency. Purchaser's standards of choice. Joint analysis. Attributes. Organizational purchaser's behavior. 


\section{INTRODUÇÃO}

$\mathrm{Na}$ década de 1990 o cenário econômico para a indústria fotográfica esteve favorável, especialmente no que diz respeito aos bancos de imagens. Com a popularização das câmeras digitais e da internet, a indústria da fotografia ampliou suas fronteiras, em termos de volume, variedade e qualidade. Existiam em 2004 aproximadamente 1000 bancos de imagem na internet (LIMA, 2007) que comercializavam imagens de vários temas, estilos e tipos de utilização, disponibilizando, por mecanismos de busca, imagens para download imediato e em alta resolução.

Um banco de imagens é composto de um conjunto de imagens em arquivo, ou seja, em estoque, e que podem ser utilizadas para fins de publicidade, ilustração, conteúdo de documentos etc. (Frosh, 2004). A empresa administradora do banco de imagem capta, cataloga e distribui as imagens de fotógrafos nacionais e internacionais. 0 cliente recebe a imagem da qual necessita, pela internet, digitalizada e adequada às suas aplicações.

Bancos de imagens costumam oferecer mais de dois milhões de imagens em seus portais, e muitos passaram a atender segmentos específicos de mercado, como aqueles especializados em esportes, medicina e saúde, natureza, personalidades, animais e beleza. Há os que comercializam filmes, imagens em movimento e imagens por assinatura. Agências de propaganda ainda são os principais clientes de um banco de imagens, mas com a popularização das imagens pela internet, os clientes variam desde uma grande indústria até um usuário individual final (LIMA, 2007).

Para os bancos de imagens que possuem uma solução e-commerce, o cliente efetua o download da imagem em tempo real, comprando os direitos de uso e não estabelecendo nenhum contato comprador-vendedor. 0 controle é feito por um software que agrega as informações de uso dadas pelo cliente na hora da compra. Se as informações estiverem corretas, as fotos são ou não liberadas para o uso solicitado. Sendo uma imagem royalty free, de uso não controlado, a venda não necessita das informações para o controle de seu uso.

Este artigo analisa os atributos considerados críticos pelos clientes de produtos de banco de imagens e sua relevância no processo de escolha do banco de imagem, em um ambiente virtual ou de e-commerce. A escolha do tema é justificada pelo fato de o mercado de imagens ainda não ter sido objeto de estudo na área de marketing organizacional (business to business) no Brasil, pelo menos em pesquisa realizada nos principais periódicos nacionais de administração (Revista de Administração de Empresas, Revista de Administração da USP e Revista de Administração Contemporânea) nos últimos cinco anos, e últimos cinco anais do Encontro Nacional da ANPAD (Associação Nacional de Pós-graduação e Pesquisa em Administração). Assim, este artigo pode contribuir para o aprimoramento do conhecimento do comportamento de escolha do comprador organizacional, com relação aos atributos percebidos em uma oferta específica em e-commerce business to business.

O artigo está assim estruturado: esta introdução apresentou o tema, objetivo e justificativa. A próxima apresenta o referencial teórico, seguido pelo método da pesquisa qualitativa e quantitativa, em que foi aplicada a análise conjunta, e a apresentação dos resultados. 0 artigo é finalizado com a discussão dos resultados e suas implicações, bem como sugestões para futuras pesquisas de marketing organizacional.

\section{REFERENCIAL TEÓRICO}




\section{Comportamento de compra organizacional}

O comportamento do comprador organizacional (ou industrial) foi definido por Webster e Wind (1972) como o processo de tomada de decisão pelo qual as organizações formais estabelecem a necessidade de bens e serviços a serem adquiridos, e identificam, avaliam e escolhem entre alternativas de marcas e de fornecedores. A literatura sobre o comportamento de compra organizacional passou por quatro grandes fases nos últimos 30 anos: de desenvolvimento de modelos conceituais (1970-1980); de retorno às origens, pelo questionamento dos fundamentos das teorias tradicionais dos anos 60 (fins dos anos 80 e início dos anos 90); de estudos mais descritivos (início da década de 1990) e de estudos do relacionamento comprador/vendedor (final da década de 1990) (Bunn, 1992).

Sheth (1996) avaliou as mudanças que ocorreram no modelo de comportamento de compra de uma organização, sugerindo que o surgimento da filosofia de gerenciamento da qualidade total incentivou o marketing reverso, partindo de clientes externos e movendo-se para trás em processos e em práticas de compra, especialmente em como estas se relacionavam com prazos mais curtos e com gerenciamento pouco eficiente de estoque. 0 autor observou que, à medida que os clientes organizacionais começassem a buscar seus principais fornecedores em uma base global de relacionamento, as empresas teriam que, internamente, criar e manter equipes dedicadas e focadas em seus clientes-chave. Este comportamento também pode ser observado no mercado de banco de imagens: tendo os clientes fácil acessibilidade aos bancos de imagens na internet, estes identificaram a necessidade de criar equipes voltadas para seus clientes e com benefícios que estimulam a fidelidade. Por exemplo, para os clientes que necessitam de um grande volume de imagens, foram criados sistemas de imagens por assinatura que oferecem um acervo ilimitado, mas com ausência de exclusividade.

Webster e Wind (1972) sugeriram um modelo de comportamento de compra organizacional e institucional tal como um processo de tomada de decisão dentro de uma organização. Neste modelo, o comportamento de compra organizacional é um processo complexo e envolve muitas pessoas, objetivos e critérios de decisão potencialmente conflitantes. Além disso, ocorre num período prolongado de tempo, requer informações oriundas de muitas fontes e abrange muitos relacionamentos inter-organizacionais. 0 processo de compra organizacional é uma forma de resolução de problemas, ou seja, uma situação de compra é criada quando alguém na organização percebe um problema, uma discrepância entre um resultado desejado e a situação atual, que possa potencialmente ser resolvido por alguma ação de compra.

A tecnologia de compra define o gerenciamento e os sistemas de informação que são envolvidos no processo de decisão de compra, tal como computadores e abordagens científicas de gerenciamento, e também define a planta e os equipamentos da organização.

Todo o comportamento de compra organizacional é um comportamento individual. Somente o indivíduo como um indivíduo ou um membro de um grupo pode definir e analisar situações de compra, tomar as decisões e implementá-las. Neste comportamento, o indivíduo é motivado por uma combinação complexa de objetivos pessoais e organizacionais, coagido pelas políticas e pelas informações adquiridas com uma organização formal e influenciado por outros membros do centro de compra (WEBSTER; WIND, 1972).

A personalidade do comprador organizacional, a motivação, a cognição e a aprendizagem são os processos psicológicos básicos que afetam sua resposta aos estímulos de compra e aos estímulos de fornecedores em potencial. 0 comprador organizacional pode, conseqüentemente, ser visto como o responsável por desencorajar decisões. É influenciado 
igualmente pelo contexto das influências interpessoais e organizacionais no qual está inserido.

O comportamento de compra organizacional é um processo de tomada de decisão comum, e as regras de tomada de decisão dos compradores organizacionais são objetos de estudo na literatura de marketing. Esforços foram feitos para prever as escolhas do fornecedor na compra organizacional usando modelos lineares da atitude, e os resultados indicaram que os compradores não usam uma combinação de regras para a tomada de decisão em vários estágios de um processo bem sucedido (VYAS; WOODSIDE, 1984). Estes autores notaram que, ao invés de procurar a melhor alternativa, o tomador das decisões normalmente preocupa-se em encontrar uma alternativa satisfatória, e que experiências em compras passadas influenciam as regras para a tomada de decisão (se alguém questiona uma decisão, um comprador pode explicar que a precedência foi usada como um guia na tomada de decisão).

\section{Organizações virtuais}

Uma organização virtual é uma rede de unidades econômicas interligadas por interesses comuns, pela partilha de recursos e por uma significativa coordenação de atividades mais eficazes no aproveitamento de oportunidades de mercado e mais eficientes na utilização dos recursos (TURBAN; KING, 2004).

Centrando a atividade nas suas principais competências, as organizações virtuais vêm apostando em estratégias de desintegração vertical que se caracterizam por: i) estabelecimento de parcerias com concorrentes; ii) crescente individualização das relações com os clientes; iii) redução do número de fornecedores (pela maior adesão ao recurso outsourcing). Tais organizações apresentam dois tipos de vantagens em relação às formas de estruturação mais tradicionais: i) estratégicas (conseguem compatibilizar as vantagens das grandes empresas, como economia de escala, poder de negociação e prestígio) e das pequenas empresas (agilidade, reduzida burocracia, custos de estrutura relativamente baixos); ii) operacionais, tais como menos e melhores meios de financiamento, redução de custos operacionais, acesso a novos métodos de gestão e redução do risco (STRAUSAK, 1998).

Existem duas abordagens principais ao se definir organizações virtuais (TURBAN; KING, 2004). A primeira refere-se a uma rede de organizações independentes, que se unem em caráter temporário pelo uso da tecnologia de informação e comunicação, visando vantagem competitiva. Um banco de imagens, por exemplo, é uma única empresa, que possui diversos fornecedores de imagens. Quando maior o número de fornecedores a integrar um banco de imagens, maior e mais diversificado será o seu acervo. A segunda abordagem define uma organização virtual como uma empresa que faz mais uso da tecnologia de informação e comunicação do que a presença física, para interagir e conduzir seus negócios. Aqui adota-se a primeira abordagem por estar condizente com o conceito de rede de empresas (SANTOS; VARVAKIS, 1999).

São quatro os tipos mais importantes de redes organizacionais (TURBAN; KING, 2004): internas, verticais, horizontais e diagonais. As redes internas consistem em grandes conglomerados cuja estruturação se baseia na desintegração em unidades de negócio interdependentes. Na prática, trata-se de grupos econômicos constituídos por empresas que seguem uma missão própria com base em opções de desenvolvimento específicas. A essas unidades é geralmente atribuída grande autonomia funcional para garantir as vantagens anteriormente expostas. As redes verticais são aquelas que, sendo criadas ao longo da cadeia de valor, se expandem para jusante ou para montante da empresa central. 0 centro 
estratégico assume um papel crítico no desenvolvimento e manutenção da rede. Com efeito, grande parte do processo de coordenação de atividades, de partilha de recursos e da gestão do clima de confiança passa por ela. As redes horizontais consistem em alianças entre firmas similares

para desenvolver ou explorar uma determinada oportunidade de negócio. Elas surgem quando várias unidades econômicas estabelecem uma parceria para desenvolver novos produtos, mercados, tecnologias ou para explorar um negócio em particular. As redes horizontais representam as parcerias existentes entre o banco de imagens e os fornecedores de imagens a fim de explorar a oportunidade de aumentar as vendas para o segmento alvo determinado. As redes diagonais são parcerias entre empresas de diversos setores que têm como objetivo usufruir as sinergias no sentido de criarem ou explorarem novas áreas de negócio. É no âmbito das novas tecnologias de informação que este tipo de rede mais se tem desenvolvido.

Para Brito e Ramos (2000), a fluidez das relações de troca é um dos principais requisitos para o surgimento e sucesso das redes empresariais, daí que a existência de "espaços" em que essas trocas se processem com facilidade e flexibilidade funcione como um dos fatores catalisadores da virtualização das organizações. Segundo os autores, é neste domínio que merecem destaque especial o que se designa por e-marketplaces. 0 e-marketplace, do lado da venda, é o mercado análogo para compradores empresariais, isto é, proporciona a eles um canal de vendas e de negociação baseado na internet, freqüentemente por meio de uma extranet. 0 banco de imagens, por exemplo, pode disponibilizar aos seus clientes uma extranet, em que estes podem adquirir as imagens de acordo com os critérios de uso, como período de utilização, local de divulgação, tamanho da imagem a ser divulgada, resolução desejada etc.

Tal como numa economia não digital, há essencialmente dois tipos de marketplaces eletrônicos: horizontais e verticais. Enquanto os horizontais agregam empresas de um mesmo setor, os verticais envolvem aquelas de diversos setores, que podem levar a um aumento do potencial de negociação, uma vez que são muito mais abrangentes (BRITO; RAMOS, 2000).

As complexas transações de compra e venda que envolvem uma forte interação humana são, em um e-marketplace, automatizadas por uma rede informatizada, abrangendo desde a negociação até o pagamento, e desde o processamento de encomendas até a respectiva entrega (TURBAN; KING, 2004). Isto faz com que a distância entre fornecedor e comprador diminua sensivelmente, criando uma economia mais desintermediada. Em contrapartida, assiste-se à emergência de novas formas de intermediação baseadas na internet, como os "cybermediaries" ou os "electronic brokers", cujo papel é primariamente a agregação e disseminação de dados pelos clientes. Uma variação neste tema é designada de "infomediary", intermediários que encontram e oferecem aos potenciais fornecedores alvo informação sobre clientes individuais. Isto implica uma reavaliação da função de intermediário, cuja possibilidade de criar valor passa, exatamente, pela quantidade e qualidade da informação que dispõe (Vandermerwe, 1999).

Neste ambiente virtual e de rede, o banco de imagem apresenta-se como um rico objeto de estudo para a compreensão do comportamento do comprador organizacional. Isto porque se trata de um produto intangível, cujos critérios da compra organizacional podem ser atributosobjetivos e subjetivos, tanto do produto quando das habilidades do próprio fornecedor. Os critérios genéricos mais comumente usados nas decisões de compra organizacional são: preço, habilidade de atender as especificações exigidas, habilidade de 
atender os cronogramas de entrega, capacidade técnica, garantias e políticas de indenização em casos de mau desempenho, desempenho passado em contratos anteriores e instalações e capacidade de produção (Berkowitz et al., 2003). Tais critérios serão especificados a seguir com base nesta pesquisa, visto a escassez de conhecimento específico sobre bancos de imagem na literatura brasileira de marketing.

\section{MÉTODO}

Esta pesquisa se dividiu em duas fases: qualitativa e quantitativa. A primeira teve o objetivo de aprimorar o problema de pesquisa, bem como definir os atributos da oferta de um banco de imagem relevantes para a escolha do comprador organizacional. A segunda fase teve o objetivo de classificar por ordem de importância tais atributos, com uso da análise conjunta.

\section{Fase qualitativa}

Esta fase consistiu de entrevistas em profundidade com dois sócios-proprietários de bancos de imagens distintos, com objetivo de obter informações do mercado, bem como levantar os atributos da oferta que achavam ser os mais relevantes para os seus clientes. As entrevistas buscaram esclarecer os seguintes fatores do comportamento do cliente: hábitos de consumo do produto e o consumo de categorias de produtos relacionados, comportamento de consumo de mídia e a reação a promoções, sensibilidade a características do bem ou serviço, preferências do cliente.

Uma outra etapa desta fase consistiu de questionários apresentados num site da internet para um grupo de 80 clientes de bancos de imagens. Os entrevistados receberam um e-mail convidando para acessar o site. Apesar de se terem sido usados questionários, a análise dos dados foi qualitativa (pois os questionários continham também perguntas abertas) e objetivou levantar os principais atributos da oferta encontrados na literatura e (des)confirmar as informações levantadas pelos dois sócios-proprietários de bancos de imagens previamente entrevistados.

Os atributos presentes na oferta de produtos no mercado de banco de imagens levantados na

fase qualitativa foram: Resolução da Imagem: a disponibilização de imagens de royalty protegido em alta resolução para a criação do layout de uma peça publicitária, por exemplo, é um grande diferencial entre os bancos de imagens. A imagem em alta resolução propicia a criação de uma prévia da peça muito próxima da arte final. Em um dos bancos de imagens brasileiros, por exemplo, os clientes de serviços por assinatura têm à sua disposição senhas distintas que possibilitam o acesso a níveis distintos de resolução de imagem. Para os clientes das agências de propaganda, um layout bem apresentado com imagens em alta resolução, faz com que a probabilidade da aprovação da campanha seja maior, pois há maior impacto em um layout apresentado à semelhança da campanha publicitária a ser publicada. Por esta razão os "art buyers" são solicitados pelos diretores de arte e de criação das agências para que deem preferência aos bancos que forneçam imagens para layout em alta resolução.

Acervo de imagens nacionais: os fotógrafos brasileiros também contribuem com suas imagens para o enriquecimento das coleções dos bancos de imagens. Imagens da natureza brasileira (flora e fauna), indústria, agricultura, aspectos culturais, geografia, política, imagens históricas dos anos 70, 80 e 90, além da produção contemporânea, abastecem um mercado internacional basicamente editorial. Dentre os compradores para editoriais destacam-se a revista de atualidades Newsweek (EUA), o jornal El País (Espanha) e o jornal Expresso (Portugal). Além destes, os acervos de imagens nacionais são procurados para atender a uma demanda de 
imagens de guias turísticos do Brasil de editoras como a Gallimard (França) e a Essencial (Portugal).

Pesquisas de imagens: Os bancos de imagens disponibilizam, em seu website, uma ferramenta de pesquisa, em que o cliente consegue buscar as imagens que mais se enquadram no perfil da peça publicitária ou layout. No entanto, caso o cliente não tenha a disponibilidade de pesquisar no website, ele pode solicitar uma pesquisa ao banco de imagem. Este, de acordo com a idéia passada pelo cliente, irá selecionar as melhores imagens para a necessidade apresentada. Com aproximadamente 100 bancos de imagem competindo na região sudeste do Brasil e com a velocidade e urgência na criação e aprovação das campanhas publicitárias, os diretores de arte e de criação não têm à sua disposição tempo hábil para pesquisar com eficácia e em um número satisfatório de fornecedores de imagens. Por esta razão as empresas de propaganda mais estruturadas e com um relacionamento profissional mais intenso com determinados bancos de imagens, solicitam para que eles façam a pesquisa respeitando a

orientação ou o briefing fornecido pela agência. Desta forma, o volume de pesquisas oferecidas, que estão dentro do layout proposto pela agência, contribui para uma tomada de decisão mais rápida e eficaz.

Imagens por assinatura: um dos serviços oferecidos por banco de imagens é o sistema de assinaturas. Algumas empresas disponibilizam até dez tipos de assinaturas ao cliente. De acordo com cada assinatura, o cliente pode baixar qualquer imagem durante o período vigente e tamanho disponibilizado em contrato. Frente à evolução das produções fotográficas e as formas de aquisições oferecidas pelos bancos de imagem, as assinaturas surgiram como uma opção de baixo custo para os clientes que necessitam de volume de imagens, mas possuem um orçamento reduzido para adquiri-as. No entanto, as assinaturas oferecem um acervo limitado, com qualidade inferior e ausência de exclusividade. Por este motivo, na maioria dos casos, este modelo de comercialização é usado principalmente pelo mercado editorial e de livros didáticos.

Características da loja virtual: as principais razões pelas quais as organizações estão migrando para o comércio eletrônico e desenvolvendo suas lojas virtuais são: redução nos custos das transações cliente-empresa, expansão do mercado, melhoria nos serviços prestados ao cliente, aumento de visibilidade, desenvolvimento de uma imagem de organização hightech, aumento do tamanho aparente, direcionamento de "tráfego" para as lojas físicas, entre outras (WEBB; SAYER, 1998). As barreiras de entrada para o desenvolvimento de uma loja virtual são mínimas ou praticamente inexistentes. 0 acesso a oportunidades é praticamente igual a todas as lojas virtuais, independentemente de seu tamanho físico.

Diversas pesquisas (EVANS; WURST, 1999; BURKE, 1996; SINGH; DALAL, 1999) têm demonstrado que características da loja virtual, como design, navegação, serviços oferecidos etc. - gera sentimentos e julgamentos dos clientes, que, por sua vez, contribuem para a formação de uma atitude diante da loja. Singh e Dalal (1999) demonstraram que sentimentos e julgamentos sobre lojas virtuais e homepages são responsáveis por cerca de $47 \%$ a $67 \%$ da variação de atitude diante dessas lojas e homepages. Também se verificou uma forte correlação entre essas atitudes e as intenções dos clientes em continuarem a explorar a loja virtual.

Um website com design agradável, ergonômico, conveniente, assim como uma navegação facilitada, também são aspectos importantes na análise de uma loja virtual. Os clientes não podem se sentir "intimidados" com a tecnologia utilizada; a navegação deve ser intuitiva e 
fácil. Características que facilitam uma navegação incluem: um botão "ajuda", mecanismos de busca, mapa do site, índices, entre outras (STEIL et al., 2001), o que também é aplicável para um banco de imagens.

A tecnologia trouxe para os bancos de imagens a agilidade das câmeras digitais, fazendo com que não exista mais arquivo físico nas empresas. A facilidade de um arquivo virtual, disponibilizando entre cinco e seis milhões de imagens na tela de um computador, faz com que o mercado exija um sistema de compra compatível com a tecnologia oferecida. 0 mercado brasileiro de banco de imagens ainda é tradicional, e há predominância de contato pessoal entre vendedor e comprador. No entanto, mercado leva todos os profissionais de fotografia a investirem em vendas online.

Preço (parcelamento com cartões de crédito): atualmente, na maioria dos bancos de imagens brasileiros, as imagens adquiridas são pagas por depósito bancário ou boleto bancário. A disponibilização de pagamentos parcelados através com uso de cartões de crédito facilita o processo de venda, portanto, em breve, será inevitável, pela natureza da própria atividade que, tanto o uso do cartão de crédito ou qualquer outro sistema com pagamentos parcelados, sejam rotinas de comercialização, fazendo com que o fluxo de atividades comerciais entre os bancos de imagens e seus clientes aumente de forma a beneficiar o consumo de imagens no mercado brasileiro.

Envio de newsletter: a newsletter é uma ferramenta direta de divulgação de novas coleções, promoções, etc. Frente à diversidade de sistemas de disponibilização de imagens no mercado se fazem necessários instrumentos de divulgação para que os distribuidores tenham acesso a informações sobre o que esta sendo disponibilizado em cada banco de imagem, o que pode ser um atributo importante presente na oferta do serviço.

Após interpretação das informações dos questionários e das entrevistas em profundidade, optou-se por se trabalhar com os seguintes atributos: imagens em alta resolução para layout, acervo de imagens nacionais, realização de pesquisa de imagens para o cliente, imagens por assinatura, e-commerce (transação possível na internet), parcelamento da compra em cartão de crédito e envio de newsletter.

Foram considerados dois ou três níveis para os atributos, conforme o QUADRO 1. Resolução

(RES) foi medida pela disponibilização de imagens para o cliente, no tamanho A3 com 300dpi's e imagens tamanho A4 com 100dpi's (por meio de senhas de acesso, para realização de layouts e posterior compra da imagem ou do de seu uso, bem como pela não disponibilização de imagens em alta resolução para layouts. Acervo (ACE) foi medido pela existência e ausência de imagens brasileiras, tais como flora, fauna, cultura, pontos turísticos, política, pessoas etc. Realização de pesquisa (PES) foi medida pela disponibilidade, ou não, de um banco de imagens realizar pesquisas para seus clientes. , a cerca do tema buscado por este cliente, por exemplo, para o seu trabalho publicitário. Imagem por assinatura (ASS) foi medida pela existência, ou não, de planos de imagens por assinatura, que representam uma opção de baixo custo para os clientes que necessitam de volume de imagens, mas possuem um orçamento reduzido para adquiri-as. Estas assinaturas oferecem um acervo limitado, com qualidade inferior e ausência de exclusividade. E-commerce (ECO) foi medido pela presença, ou não, de transação via internet oferecida pelo banco de imagem, já que isto propicia ao cliente vantagens como a disponibilidade de compra 24 horas por dia, nos sete dias na semana; a interatividade que permite ao cliente o controle do fluxo de informações e a comparação imediata das imagens. Condições de pagamento (CPG) foi medida pela 
possibilidade, ou não, de parcelamento do valor da compra da imagem em cartão de crédito.

Comunicação (COM) foi medida pelo envio, ou não, de newsletters aos clientes, visando comunicá-los sobre promoções, novas imagens, novos fornecedores de imagens etc.

Quadro 1: Atributos e níveis obtidos na fase qualitativa

\begin{tabular}{|l|l|}
\hline \multicolumn{1}{|c|}{ Atributos } & \multicolumn{1}{c|}{ Níveis } \\
\hline \multirow{2}{*}{ Resolução - RES } & Imagens A3* 300dpi** para layout \\
\cline { 2 - 2 } & Imagens A4 100dpi para layout \\
\cline { 2 - 2 } Acervo - ACE & Sem imagens em alta resolução \\
\hline \multirow{2}{*}{ Realização de pesquisa - PES } & Com imagens nacionais \\
\cline { 2 - 2 } Imagens por assinatura - ASS & Sem imagens nacionais \\
\hline \multirow{2}{*}{ E-commerce - ECO } & Com realização de pesquisas de imagens para o cliente \\
\cline { 2 - 2 } Condições de Pagamento - CPG & Sem realização de pesquisas de imagens para o cliente \\
\hline \multirow{2}{*}{ Comunicação - COM } & Com imagens por assinatura \\
\cline { 2 - 2 } & Sem imagens por assinatura \\
\hline & Com E-commerce \\
\cline { 2 - 2 } & Sem E-commerce \\
\cline { 2 - 2 } & Com parcelamento da compra em cartão de crédito \\
\cline { 2 - 2 } & Sem parcelamento da compra em cartão de crédito \\
\cline { 2 - 2 } & Com envio de newsletter \\
\cline { 2 - 2 } & Sem envio de newsletter \\
\hline
\end{tabular}

*A3 e A4 referem-se ao tamanho da imagem (A3: 297mm largura X 420mm altura; A4: 210mm largura $\mathrm{X} 297 \mathrm{~mm}$ altura);

**DPI é a abreviação para dots per inch, ou pontos por polegada. Trata-se de uma medida de resolução para imagem em tela ou imagem impressa (quanto maior o valor do dpi, mais nítida e detalhada será a imagem).

\section{Fase quantitativa}

A análise conjunta, aqui adotada, é uma técnica de análise multivariada usada especificamente para analisar a preferência entre um conjunto de ofertas ou produtos, pela avaliação de utilidade que os clientes atribuem a cada uma das características ou atributos do produto (Hair et al., 1992:392). Uma das vantagens do uso da análise conjunta está na apresentação dos atributos e seus níveis, o que aproxima os respondentes da situação real de compra, na qual a escolha por um produto se dá, entre outros fatores, por aquele que possui a melhor combinação de atributos. Adicionalmente, evita-se a dificuldade inerente do respondente em hierarquizar a importância de múltiplos atributos (Churchill, 1995).

Na análise conjunta o pesquisador constrói uma oferta (bem ou serviço), mesmo hipotética, combinando níveis de atributos. Tais níveis são os valores possíveis para cada variável que o pesquisador manipula e que representa um atributo específico. De acordo com Aaker et al. (2001), à medida que o número de atributos e níveis aumenta, a tarefa de julgar os perfis individuais torna-se muito complexa para o respondente. Desta forma, com mais de cinco ou seis atributos, existe uma grande possibilidade de sobrecarga de informações, o que pode levar o respondente a ignorar as variações nos fatores menos importantes.

No presente artigo o número de ofertas iniciais a serem apresentadas seriam $3 \times 2 \times 2 \times 2 \times 2 \times 2 \times 2=192$ (um atributo com três níveis e seis com dois níveis cada), o que seria impossível de se operacionalizar num levantamento de campo. Portanto, empregou-se o 
Planejamento Fatorial Fracionário, descrito por Malhotra (2006:555), para reduzir o número de perfis de estímulos para 16.

Na análise conjunta, analisa-se a influência de cada atributo e de cada valor dado ao atributo referente ao julgamento de um respondente quanto à utilidade (HENRIQUE; SOUZA, 2006).

A utilidade é um julgamento subjetivo de preferência por um indivíduo que representa o valor do objeto específico. A análise de utilidade é uma medida numérica das preferências individuais para um determinado nível de atributo. Quanto maior o valor, maior a preferência.

O questionário consistiu em estímulos visuais, com a montagem de cada um dos tipos de bancos de imagens (16 cartões ou bancos de imagem). Cada respondente foi instruído a demonstrar sua intenção de compra em uma escala Likert de cinco pontos (certamente não compraria a certamente compraria) para cada uma das 16 ofertas.

Para o modelo foi usada uma regressão de variáveis dummies (Malhotra, 2006). Como o objetivo era estabelecer uma classificação de preferências (variável dependente), foram usadas oito variáveis dummies. A função utilidade foi assim definida:

$$
U=b_{0}+b_{1} X_{1}+b_{2} X_{2}+b_{3} X_{3}+b_{4} X_{4}+b_{5} X_{5}+b_{6} X_{6}+b_{7} X_{7}+b_{8} X_{8}
$$

X1 e X2 referem-se ao atributo Resolução e X3, X4, X5, X6, X7 e X8 referem-se aos atributos Acervo, Realização de pesquisa, Imagens por assinatura, E-commerce, Condições de

Pagamento e Comunicação, respectivamente. Partindo-se da função utilidade, pôde-se definir os parâmetros b0, b1, b2, b3, b4, b5, b6, b7 e b8, o que significa levantar a importância de cada atributo usando a diferença entre a maior e a menor utilidade de cada atributo, dividido pelo termo b0. Os dados foram analisados no software SPSS, com a confirmação de que as ofertas possuem ortogonalidade entre atributos e seus níveis.

Foram enviados emails solicitando resposta à web survey para uma amostra inicial de 1000 clientes de bancos de imagens, representados por agências de publicidade, editoras de livros didáticos e empresas de editoriais, foi selecionada nos estados do Rio de Janeiro, São Paulo,

Espírito Santo e Minas Gerais (região sudeste do Brasil). A taxa de resposta foi de 7,8\%, totalizando 78 questionários válidos (a amostra caracteriza-se, portanto, como sendo de conveniência, não probabilística).

\section{RESULTADOS}

Das 78 empresas que participaram da pesquisa, 61\% pertencem ao estado de São Paulo, 29\% ao estado do Rio de Janeiro e $10 \%$ dos demais estados. A maior parte da amostra (60\%) foi composta de empresas que possuem no máximo 49 funcionários, e 84\% correspondem a empresas brasileiras. Quarenta e dois por cento dos compradores são gerentes, sócios proprietários ou CEO's, 47\% são diretores de arte, art buyers ou assistentes de arte e 11\% são estagiários. Os resultados da análise conjunta são apresentados na TABELA 1. 
TABELA 1: Utilidade para cada nível de atributo

\begin{tabular}{|l|l|l|}
\hline \multicolumn{1}{|c|}{ Atributos } & \multicolumn{1}{|c|}{ Níveis } & \multicolumn{1}{c|}{ Utilidade } \\
\hline \multirow{4}{*}{ Resolução - RES } & Imagens A3* 300dpi** para layout & 0,6086 \\
\cline { 2 - 3 } & Imagens A4 100dpi para layout & 0,3290 \\
\cline { 2 - 3 } & Sem imagens em alta resolução & $-0,6414$ \\
\hline \multirow{2}{*}{ Acervo - ACE } & Com imagens nacionais & 0,2549 \\
\cline { 2 - 3 } & Sem imagens nacionais & $-0,2549$ \\
\hline \multirow{2}{*}{ Realização de pesquisa - PES } & Com realização de pesquisas de imagens para o cliente & 0,2484 \\
\cline { 2 - 3 } & Sem realização de pesquisas de imagens para o cliente & $-0,2484$ \\
\hline \multirow{2}{*}{ Imagens por assinatura - ASS } & Com imagens por assinatura & 0,0905 \\
\cline { 2 - 3 } & Sem imagens por assinatura & $-0,0905$ \\
\hline
\end{tabular}

\begin{tabular}{|l|l|l|}
\hline \multirow{2}{*}{ E-commerce- ECO } & Com E-commerce & 0,1135 \\
\cline { 2 - 3 } & Sem E-commerce & $-0,1135$ \\
\hline \multirow{2}{*}{ Condições de Pagamento - CPG } & Com parcelamento da compra em cartão de crédito & 0,1924 \\
\cline { 2 - 3 } & Sem parcelamento da compra em cartão de crédito & $-0,1924$ \\
\hline \multirow{2}{*}{ Comunicação - COM } & Com envio de newsletter & 0,0082 \\
\cline { 2 - 3 } & Sem envio de newsletter & $-0,0082$ \\
\hline \multicolumn{2}{|c|}{ Constante do modelo 2,3388 } \\
\hline
\end{tabular}

$\mathrm{O}$ fator R de Pearson teve um valor igual a 0,975; com uma significância igual a 0,0000. Já o valor do Tau de Kendall foi de 0,891 com a mesma significância de 0,0000. Isto significa que existe uma excelente associação entre as variáveis apresentadas no modelo na análise das preferências do respondente.

O atributo mais relevante na escolha do banco de imagem, como mostra a GRÁFICO 1, é a disponibilidade de imagens em alta resolução para layout. Sua importância relativa é de 40,78\%. 0 nível de formato A4/100dpi produz um aumento na utilidade geral do comprador de 0,3290; enquanto que o nível de formato A3/300dpi aumenta em 0,6086 (o nível "sem imagens em alta resolução" reduz em 0,6414 a utilidade geral do comprador).

GRÁFICO 1: Importância relativa dos atributos

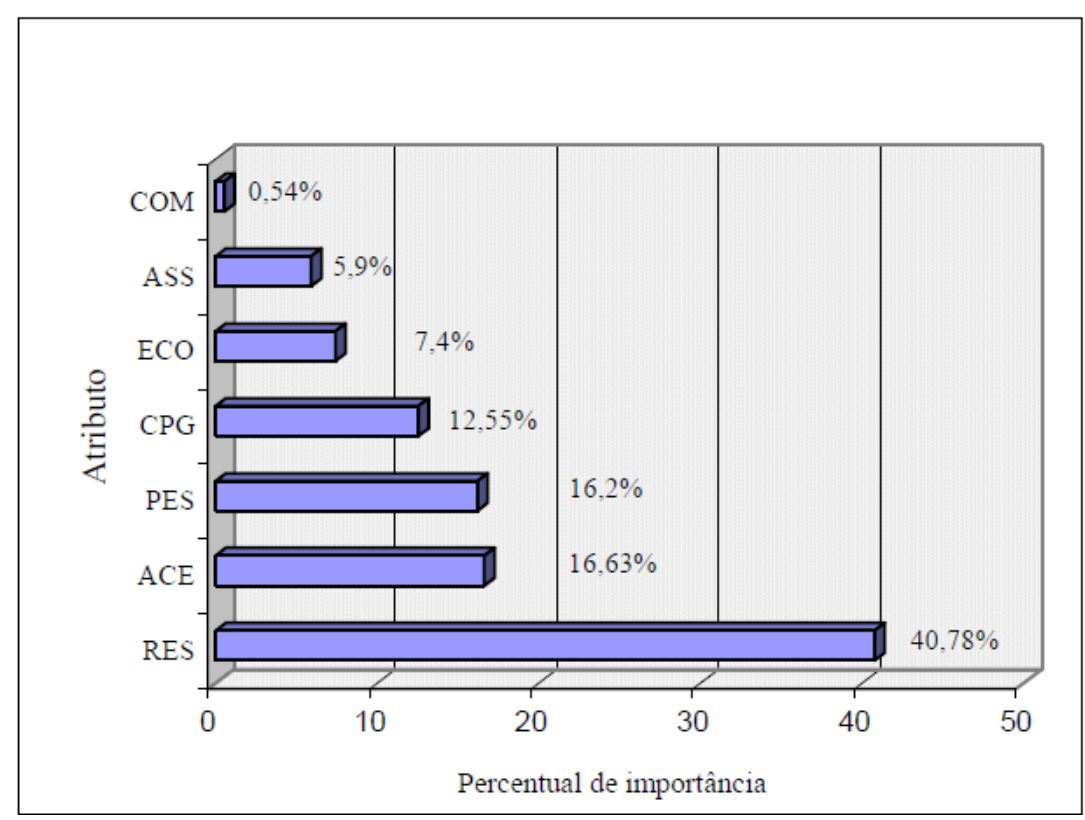


Frente a maior freqüência de empresas do estado de São Paulo na amostra respondente, procurou-se analisar a relevância dos atributos em questão de duas maneiras: a primeira somente no estado de São Paulo e a segunda nos demais estados da região Sudeste exceto São Paulo. 0 atributo mais relevante para a sub-amostra de São Paulo também foi a disponibilidade de imagens em alta resolução para o layout, seguido da realização de pesquisas e da existência de um acervo de imagens nacionais no banco de imagem. 0 parcelamento das compras das imagens segue com 14,6\% de importância enquanto a existência de e-commerce, as imagens por assinatura e o envio de newsletter, juntos, correspondem a 12,54\% (o atributo "envio de newsletter" foi o menos relevante, com 1,03\%).

No que diz respeito à mesma análise com relação aos demais estados da região Sudeste, exceto São Paulo, os resultados apontam diferenças na relevância dos atributos: a disponibilidade de imagens em alta resolução para o layout do cliente continua sendo a mais importante, com 47,29\%. No entanto, o segundo atributo mais importante deixa de ser a realização de pesquisas para o cliente e passa a ser a existência de um diversificado acervo de imagens nacionais. A realização de pesquisas para os clientes, que anteriormente representavam 18,44\%, agora surgem com uma relevância de 10,8\%. O parcelamento da compra das imagens reduz a sua importância de $14,6 \%$ para $6,98 \%$. Os estados do Rio de Janeiro, Espírito Santo e Minas Gerais dão mais importância às imagens por assinatura $(8,53 \%)$ do que o estado de São Paulo (4,87\%) (em ambas as análises o atributo "envio de newsletters" permanece próximo de 1\%).

Da mesma forma realizou-se um comparativo da relevância dos atributos entre as pequenas empresas (até 49 funcionários) e as demais. A disponibilidade de imagens em alta resolução teve importância de 37,37\% para as pequenas empresas e 46,33\% nas demais. A existência de um diversificado acervo de imagens nacionais teve $13,32 \%$ nas pequenas empresas e $22,03 \%$ nas demais. 0 parcelamento da compra com cartão de crédito teve importância de 15,74\% para as pequenas empresas, mas não foi tão relevante para as demais $(7,34 \%)$. Da mesma forma, a realização de pesquisas para os clientes (pequenas empresas $=20,93 \%$ ) perdeu importância nas demais empresas $(8,47 \%)$. Nos dois grupos o grau de importância do envio de newsletter é praticamente nulo.

A seguir é feita uma análise dos atributos mais relevantes observados nesta pesquisa, as implicações dos resultados encontrados e sugestões para futuras pesquisas.

\section{CONSIDERAÇÕES FINAIS}

Pelos resultados apresentados, o atributo mais relevante na escolha do banco de imagens ideal na amostra da região sudeste é a disponibilidade de imagens em alta resolução para o layout do cliente. Uma primeira explicação para esta preferência pode ser a necessidade do cliente de apresentar o seu layout para a aprovação, quase como uma arte final, o que a valoriza perante os tomadores de decisão da empresa. Neste sentido, este atributo pode ser um importante argumento de venda e de comunicação do produto.

0 segundo atributo mais importante foi a existência de acervo de imagens nacionais. Isso provavelmente se deve ao fato de que a barreira dos direitos de imagens, tais como modelos, personalidades, marcas etc., citado por Lima (2007), faz com que os custos se elevem, inflacionando a produção, o que não acontece com os bancos de imagem que recebem imagens com estes direitos liberados. Isso faz com que ainda haja uma carência deste tipo de imagem no mercado fotográfico brasileiro. 
Os diretores de arte e de criação geralmente não têm à sua disposição a facilidade de pesquisar um número satisfatório de fornecedores de imagens. Desta forma as empresas de propaganda mais estruturadas e com um relacionamento profissional mais intenso com determinados bancos de imagens solicitam para que eles façam a pesquisa respeitando a orientação ou o briefing fornecido pela agência, o que contribui para uma tomada de decisão mais rápida e eficaz. Isto pode explicar o fato do atributo "realização de pesquisas para o cliente" ser o terceiro mais relevante na decisão de escolha pelo banco de imagem.

A possibilidade do parcelamento das compras pelo uso de cartão de crédito se apresenta como o quarto atributo mais relevante, seguido da existência de e-commerce, das imagens por assinatura e do envio de newsletter. Entretanto, ao se segmentar a amostra, esta ordem de relevância se altera, exceto pelo atributo "disponibilidade de imagens em alta resolução para o layout do cliente" que em todos os casos é caracterizado como o atributo mais importante, e o envio de newsletter como o menos importante. Por exemplo, a amostra de pequenas empresas valoriza o parcelamento das compras pelo uso de cartão de crédito, enquanto que as demais empresas da amostra tendem a dar bem menos importância a este atributo.

Se se considerar que as pequenas empresas são as que possuem menos tempo no mercado, pode-se corroborar com Ozanne e Churchill (1971), quando estes afirmam que a associação entre fatores de direcionamento de compra e a idade da empresa são moderadamente sugestivos, já que os grupos tomadores de decisão, em algumas empresas mais jovens, tendem a ser mais influenciados pelos atributos dos produtos do que por outros fatores.

Para Vyas e Woodside (1984), é importante identificar as regras de tomada de decisão utilizadas pelos compradores em um processo bem sucedido. 0 conhecimento destas regras é crucial para que ações eficazes sejam implementadas no mercado. Segundo os autores, para o comportamento de compra organizacional, o centro de compras é a unidade relevante de análise para o processo de investigação da escolha do melhor fornecedor. 0 centro de compra agrega todos os membros de uma organização que se envolvem no processo de compra de um bem ou de um serviço em particular.

Este artigo apresenta limitações. Por ser um estudo transversal, não se tem capacidade de detectar mudanças resultantes da medição repetida das mesmas variáveis na mesma amostra, ou seja, não há possibilidade de se examinar mudanças no comportamento do cliente organizacional ao longo do tempo. Quanto ao método de levantamento, os entrevistados podem ser incapazes de dar a informação desejada, ou ficar relutantes. Além disso, as questões estruturadas podem resultar em perda da validade para certos tipos de dados, como crenças individuais (MALHOTRA, 2006:183).

No âmbito das implicações gerenciais o presente estudo propicia aos tomadores de decisão de bancos de imagens fatores que poderão torná-los mais competitivos. 0 primeiro fator é o custo menor de busca. Os mercados eletrônicos reduzem o custo de buscar informações sobre um bem ou serviço. Isto pode ter um forte impacto sobre a concorrência, por propiciar aos clientes pesquisas prontas de acordo com o briefing informado. 0 segundo fator a ser considerado é a diferenciação e personalização. A diferenciação envolve fornecer um bem ou serviço que geralmente não está disponível em outros lugares. Além disso, o comércio eletrônico permite a personalização ou a customização de bens e serviços. A personalização é a possibilidade de se adequar um bem, um serviço ou um conteúdo de internet às preferências de clientes específicos.

Corroborando com Turban e King (2004), pode-se dizer que a concorrência entre empresas 
está sendo substituída pela concorrência entre redes. A empresa que tiver melhores redes, recursos publicitários e relacionamentos com outras empresas na internet terão vantagem estratégica.

Como sugestão para pesquisas futuras, recomenda-se analisar uma nova forma de comercialização de imagens não contemplada nesta pesquisa: o sistema microstock, que é representado pela massificação do acesso e uso de imagens para qualquer fim com um custo reduzido, em que a compra se faz unicamente por um cartão de crédito com a aquisição de pacotes de créditos que são transformados em fotografias, de acordo com o tamanho e quantidades desejadas. Este novo formato permite que o cliente adquira uma fotografia por menos de US $\$ 1,00$ com o uso liberado, indefinido e com seus direitos autorais protegidos. $\mathrm{Na}$ prática, é um grande banco de imagens, em que se paga por créditos e os troca por arquivos fotográficos.

\section{REFERÊNCIAS}

AAKER, David. A., KUMAR, V., DAY, George. S., Pesquisa de Marketing. São Paulo, Editora Atlas, 2001.

BERKOWITZ, Eric N.; KERIN, Roger A.; HARTLEY, Steven W.; RUDELIUS, William; Marketing. São Paulo: LTC, 2003.

BRITO, Carlos Melo; RAMOS, Carla; Comércio Electrônico: relação com parceiros de negócio. Porto: Sociedade Portuguesa de Inovação, 2000.

BUNN, M. D. Understanding Organizational Buying Behavior: The Challenges of the 1990s. Review of Marketing - American Marketing Association, vol. 4, 1992, p. 227- 259.

BURKE, Raymond. Virtual Shopping: Breakthrough in Marketing Research. Harvard Business Review, v. 74, n. 2, p. 120-131, March-April 1996.

CHURCHILL, Gilbert A. Marketing research: methodological foundations. 6. ed. Orlando: Dryden Press, 1995

EVANS, Philip; WURSTER, Thomas. Getting Real About Virtual Commerce. Harvard Business Review, v. 77, n. 6, p. 85-94, November-December 1999.

FROSH, Paul; Image factory: consumer culture, photography and the visual content industry. Berg Publishers, 2004.

HAIR, J.; ANDERSON, R.E.; TATHAN, R.L.; BLACK, W.C. Multivariate Data Analysis with Readings, 3 ed., Singapore: Maxell Macmillan Publishing, 1992.

HENRIQUE, Jorge Luiz; SOUZA, Rosana Vieira. O Uso da Técnica de Análise Conjunta na Pesquisa em Marketing: uma Avaliação das Publicações Brasileiras. In: Anais... EnANPAD 2006.

LIMA, Jorge. Publicação eletrônica. [mensagem pessoal]. Mensagem recebida por <camila.mexgemp@gmail.com> em 16 jan. 2007.

MALHOTRA, Naresh K. Pesquisa de Marketing: uma orientação aplicada. 4⿳⺈冂a Ed., Porto Alegre, Bookman, 2006.

OZANNE, Urban B; CHURCHILL, Gilbert A. Jr. Five Dimensions of the Industrial Adoption 
Process. Journal of Marketing Research, Vol. 8, No. 3 (Aug., 1971), pp. 322- 328

RAMOS, Anatália Saraiva Martins; VELDMAN, Selma Monteiro da Silva. Relacionamento com o Cliente através da Web: um Estudo Teórico-Exploratório. In: Anais... EnANPAD 2000.

SHETH, Jagdish N. Organizational buying behavior: past performance and future expectations. Journal of Business \& Organizacional Marketing Vol. 11 No. 3/4 1996, p. 7-24.

SINGH, Surenda; DALAL, Nikunj. Web Home Pages as Advertisements. Communications of the ACM, v. 42, n. 8, p. 91-98, 1999.

STEIL, Andréa Valéria; PACHECO, Roberto Carlos dos Santos; BARCIA, Ricardo Miranda. Uma Pesquisa Sobre os Atributos da Interface das Organizações Virtualizadas no Cenário Brasileiro. In: Anais... EnANPAD 2001.

STRAUSAK, Nicole. Resumée of VoTalk. In: SIEBER, Pascal, GRIESE, Joachim (eds.). Organizational Virtualness. Proceedings of the VoNet - Workshop, April 27-28, 1998. Bern: Simona Verlag Bern, 1998. p. 9-24.

TURBAN, Efraim; KING, David; Comércio Eletrônico - Estratégia e Gestão. São Paulo: Pearson Education, 2004.

WEBB, Brian ; SAYER, Ruth. Benchmarking Small Companies on the internet. Long Range Planning, v. 31, n. 6, p. 815-827, 1998.

WEBSTER,Jr., F.; WIND,Y. Organizational Buying Behavior. Englewood Cliffs, N.J.:PrenticeHall, 1972.

VANDERMERWE, Sandra; “The Electronic 'Go-between Service Provider': A New 'Middle' Role Taking Centre Stage”. European Management Journal, Volume 17, № 6, Dezembro, Pergaman, Oxford, pp 598-608, 1999.

VYAS, Niren; WOODSIDE, Arch G.; An Inductive Model of Organizational Supplier Choice Precesses. Journal of Marketing v. 48, Winter, 1984. 